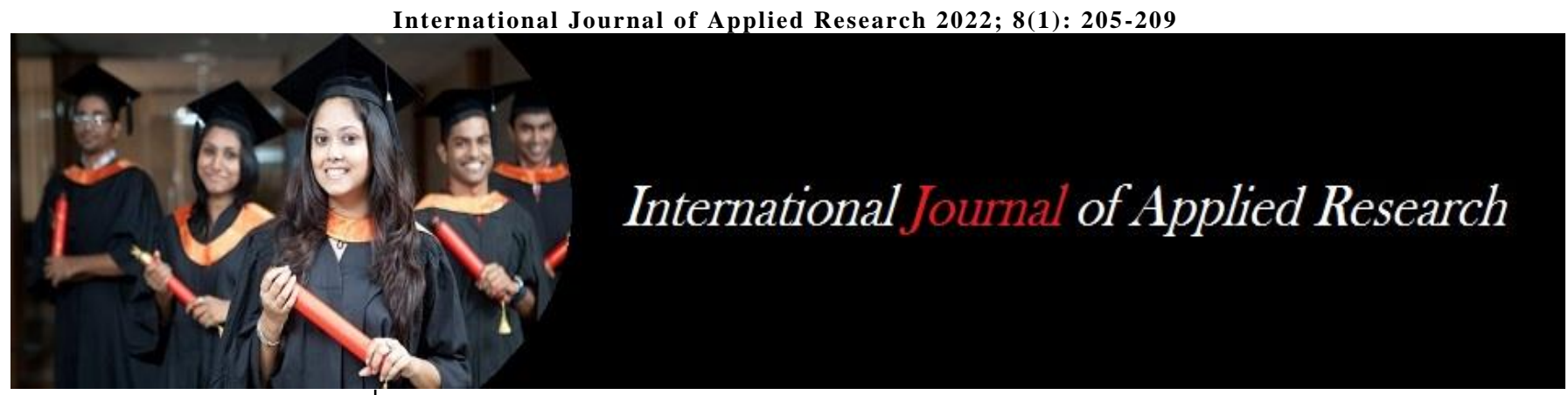

ISSN Print: 2394-7500

ISSN Online: 2394-5869

Impact Factor: 8.4

IJAR 2022; 8(1): 205-209

www.allresearchjournal.com

Received: 05-11-2021

Accepted: 13-12-2021

Basanta Sonowal

Associate Professor of

Pathology, JMCH, Jorhat,

Assam, India

Aparna Langthasa

Associate Professor of

Pathology, JMCH, Jorhat,

Assam, India

Prasanta kr. Baruah

Professor of Pathology, JMCH,

Jorhat, Assam, India

\section{Incidence of midline neck mass (A retrospective cyto- morphological study, at Jorhat Medical College, Assam)}

\section{Basanta Sonowal, Aparna Langthasa and Prasanta kr. Baruah}

DOI: https://doi.org/10.22271/allresearch.2022.v8.i1d.9338

\section{Abstract}

Introduction: Midline neck mass presents varying degrees of enlargements in front of the neck encompasses thyroglossal duct/cyst, solitary thyroid cyst, thyroid neoplasm.

Objective: To find out the incidence of midline mass by FNAC in Jorhat Medical College \& Hospital from the period October 2020 to September 2021.

Materials and Method: one year retrospective, qualitative cross sectional, observational study done in 72 nos.of different cases of midline mass and FNAC was the first mode of examination in all cases referred to us.

Result: Reporting of the cases was followed by New Bethesda system of reporting thyroid cytopathology (TBSRTC) which offers very clean concept clinically well explainable to our clinician.

On FNAC reporting $60-70 \%$ of cases had simple colloid goiter, followed by hyperthyroidism that was associated with huge nodularity and thyrotoxic features.

Few cases of AUS/FLUS were reported as per criteria laid down by TBSRTC Bethesda grading.

Conclusion: In this study, goiter in females which constitute nearly $70-80 \%$ between the $3^{\text {rd }}$ and $4^{\text {th }}$ decades of life. FNAC resulted with $97 \%$ sensitivity about $95 \%$ specificity with high Positive predictive value. FNAC found to be most economical, quick and gold standard, easy to interpret by both the pathologist and the clinician till date.

Keywords: Neck mass, fine needle aspiration cytology, goitre

\section{Introduction}

Visible swelling in front of the neck in common scenario, especially in young and elderly females in developing countries. Persons residing in and around hills and mountains are the common sufferers, where the nutritional value is less food and water. Cases of such neck swelling are seen, near railway stations and most of them are otherwise healthy, mobile and can perform their day to activity without any difficulties. Only a few categories complain associated with cosmetic deformity or features of clinical thyroditis or toxic features requires clinical evaluation and surgical interventions.

Hurley D.L, Gharib L et al., found that epidemiology of midline mass and in the United States; the incidence of such goiters was approximately $0.1 \%$ to $1.5 \%$ per year, translating into 250,000 new nodules annually. They also concluded that FNA results are pivotal to assess cancer risk in patient management for prominent palpable and suspicious nodules. Chest radiography, high-resolution ultrasonography, and computed tomography help to delineate the size and extent of a goiter in evaluating compression symptoms

Examining closely one can reveal a single solitary nodular (SN) swelling (solid or cystic) or in others multi nodular goiter (MNG) with huge swelling of varying sizes with tortuous superficial veins. Many of them complain of visible pulsations over the swelling with itching and redness.

Cases attending in ENT and General surgical OPD for midline neck swelling requires expert clinical evaluation from present history, up to thyroid function tests and presently cytological and histopatholical workup with immune histochemical analysis for grading and staging of clinical carcinoma cases as and when necessary. Now a day's genetic profiling, genomics of carcinoma are equally important using very sophisticated tools whenever possible for early detection, treatment and further management including assessing minimal residual disease in some patients under treatment.
Corresponding Author: Basanta Sonowal Associate Professor of Pathology, JMCH, Jorhat, Assam, India 
Knobel M et al. found that the current classification divides goiter into diffuse and nodular, which, (is mainly due deficiency of iodine, increase in serum thyroid-stimulating hormone (TSH) level, natural goitrogens, smoking, and lack of selenium and iron) may be further subdivided into toxic (associated with symptoms of hyperthyroidism, suppressed TSH or both), or nontoxic (associated with a normal TSH level). Nodular thyroid disease with the presence of single or multiple nodules requires evaluation due to the risk of malignancy, toxicity, and local compressive symptoms. Measurement of TSH, accurate imaging with highresolution ultrasonography or computed tomography, and fine-needle aspiration biopsy are the appropriate methods for evaluation and management of goiter.

\section{Material and Method}

The present study was a qualitative, hospital based cross sectional, retrospective study for a period of one year (October 2020 to Sept 2021) at Jorhat Medical College \& Hospital, Jorhat, Assam. During the study period, detailed history and particulars of the patients were recorded. A history of short duration $\mathrm{H} / \mathrm{O}$ of swelling, whether associated with pain or not, H/O sleep disorder, associated with hoarseness of voice, difficulty in swallowing, unusual fatigue, weakness, breathlessness etc.

The swelling was examined locally like raise of temperature, tests for deglutition, examination of presence of fluid, presence of pulsation.

As per protocol written consent was obtained from all the patients and explained to co-operate. FNAC was done under aseptic conditions using $23 \mathrm{G}$ needles with $10 \mathrm{cc}$ or $20 \mathrm{cc}$ disposable syringes. Usually two/ three passes were made, if necessary little more attempts were made. If the swelling was cystic, fluid was aspirated. The material so aspirated was immediately transferred onto glass slides, $2 / 3$ nos of slides of which were air dried and half of them alcohol fixed for Giemsa stain and Papanicolaou stain, respectively.

After satisfactory stained, smears were satisfactorily evaluated according to the Bethesda system of reporting thyroid lesions. Smears and the number cellular smears examined by cytologist were considered adequate for evaluation if it good/satisfactory smear contained at least six well-preserved and well-stained follicular groups, each containing at least ten cells.

In cases of colloid cysts, abundant thick colloid obtained was considered as adequate for diagnosis, irrespective of a minimum number of follicular cells. Smears showing atypical cells were never considered inadequate, regardless of cellularity.

\section{Observation and Results}

Total 72 nos of cases were found in the study period from October 2020 to Sept 2021. Out of 72 no.of cases 52 female and 20 nos. males. Age representation was started from 15 years to $70 \mathrm{yrs}$ with, a mean age $40 \mathrm{yrs}$. The youngest patient was 15 yrs old girl with solitary thyroid nodule and the oldest patients was 70 yrs old lady multinodular goiter with thyro-toxic features with palpable neck gland.

Majority of the cases were presented with midline neck mass e.g, thyroid swelling moved with deglutition. 20 cases were found to swelling with deglutition and protrusion of tongue which later confirmed to cystic thyroid and benign swelling. Those cases were confirmed by FNAC that was consistent with clinical findings.

After explain the procedure (preferably in local language) the nature of FNAC all the patients co-operated with cytologist. Few of them required repeat FNAC due to some technical problem and they well tolerated in next settings.

Aspirated material were hemorrhagic (32 nos.), colloid and cystic 20nos) and rest of cases showed good cellularity of aspiration. Total 55 cases were satisfactory for interpretation based on Bethesda system of classification of thyroid cytology while rest of the cases showed un satisfactory.

As per routine cytological study more than 50 cases in the study were diagnosed goiter $(n=32)$ nos $(44.4 \%)$, Colloid goiter with cystic change ( $\mathrm{n}=3$ nos) $(4.16 \%)$, lymphocytic thyroditis $(n=19)$ nos $(26.39 \%)$, follicular adenoma $(n=13)$ nos $(18.05 \%)$, Follicular carcinoma( $n=3$ nos) (4.16) and papillary carcinoma ( $\mathrm{n}=2$ nos) $(2.8 \%)$ consecutively.

According to the Bethesda system of reporting thyroid lesions, nondiagnostic category (Group 1) included 26 cases (4.29\%), and histopathology was not available in any of the case of this category. Out of 580 satisfactory samples, 501 $(82.67 \%)$ cases were diagnosed as

benign (Group 2), $5(0.82 \%)$ cases were in the category of atypia of undetermined significance (AUS)/atypical follicular lesion of undetermined significance (Group 3), 55 $(9.07 \%)$ cases were diagnosed as suspicious for Follicular Neoplasm (SFN) (Group 4), 7 (1.15\%) cases were suspicious for malignancy (SM) (Group 5), and 12 (1.98\%) cases were malignant (Group 6).

- Group 1: Inadequate/nondiagnostic category-02 aspirates $(2.8 \%)$ of total cases) were categorized as inadequate for evaluation or nondiagnostic

- Group 2: Benign lesions included colloid goiter (4.2\%, $n=3$ ), Goitre $(44.4 \%, n=32)$, Hasimoto/lymphocytic thyroiditis $(22.2 \%, n=16)$, adenomatous goiter/hyperplastic nodule $(16.6 \%, n=12)$,

- Group 3: AUS/atypical follicular lesion of undetermined significance (AFLUS) - Two cases $(2.7 \%)$.

- Group 4: FN/SFN -FN, 03cases (4.2\%) as adenomatous goiter.

- Group 5: SM - included two cases of papillary carcinoma (including a case of follicular variant of papillary carcinoma), one case of $\mathrm{FN},(2.7 \%)$

- Group 6: Malignant - nil.

Table 1: Male to Female ratio, in our study, out of 72 Nos. 52 were female and 20 male

\begin{tabular}{|c|c|c|}
\hline Clinical cases & Male (\%) & Female (\%) \\
\hline 72 & $20(27.7 \%)$ & $52(72.3 \%)$ \\
\hline
\end{tabular}




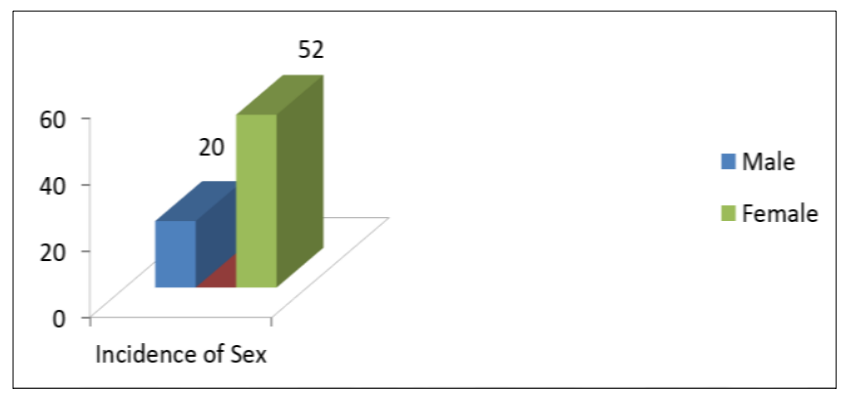

Fig 1: Bar showing the sex incidence

Table 2: Types of different tumors

\begin{tabular}{|c|c|c|c|c|c|c|}
\hline Colloid Goitre & Colloid goiter+cystic change & Lyphocytic throditis & Foll.adenoma & Foll.car & Pap.car & Total \\
\hline 32 & 03 & 19 & 13 & 03 & 02 & 72 nos \\
\hline
\end{tabular}

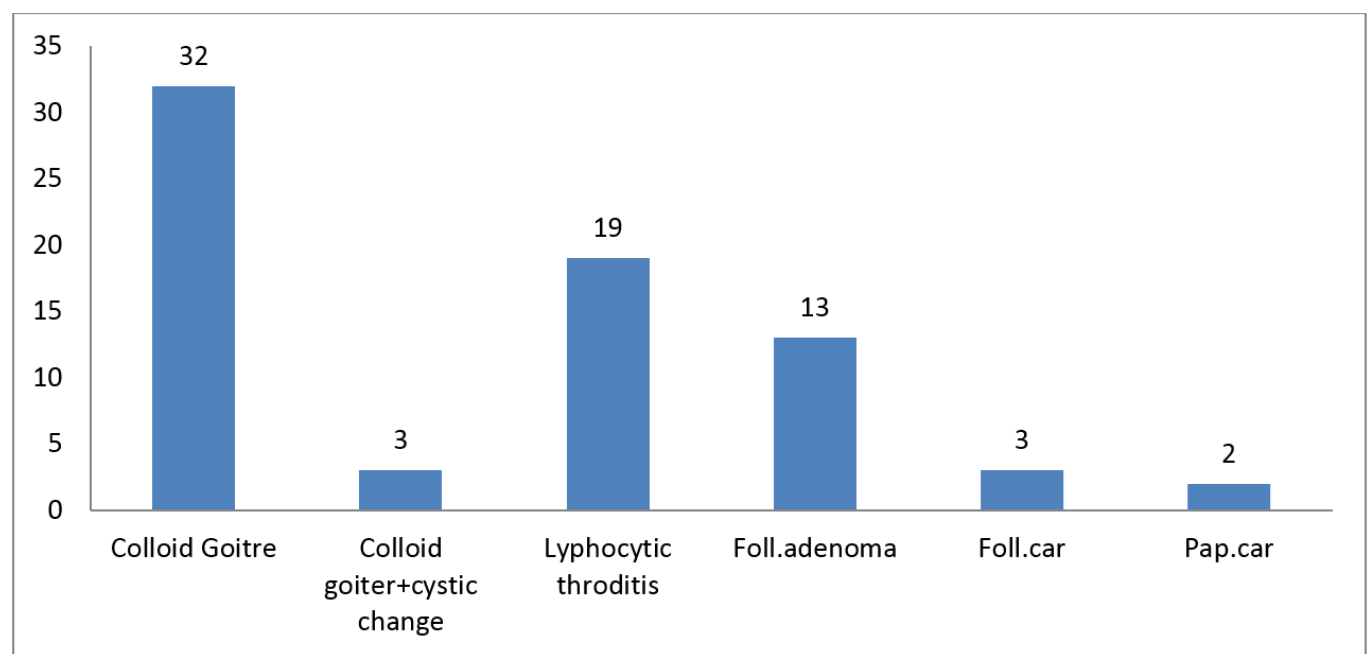

*P- value is less than 0.0001 , highly significant

Chi square $=59.33$ with 5 d.f

Fig 2: Types of different tumors (Total cases 72)

Table 3: Table showing gender frequency of tumours

\begin{tabular}{|c|c|c|c|}
\hline Types of Different tumurs & Male & Female & P- Value \\
\hline Colloid Goitre & 9 & 23 & \\
\hline Colloid goiter+cystic change & 1 & 2 & \\
\hline Lyphocytic throditis & 5 & 14 & \multirow{2}{*}{ P-value $=0.9671$} \\
\hline Foll.adenoma & 4 & 9 & \multirow{2}{*}{ Chi square value $=0.9417$ with 5 d.f } \\
\hline Foll.car & 1 & 2 & \\
\hline Pap.car & 0 & 2 & \\
\hline Total & 20 & 52 & \\
\hline
\end{tabular}

*P-value $>0.05$, not significant

Table 4: Clinical features

\begin{tabular}{|c|c|c|}
\hline Chief Complains & Total no. of cases & p-value \\
\hline Visible swelling & $\mathbf{7 2}$ \\
\hline Pain & 06 \\
\hline Intolerance to heat/cold & 03 \\
\hline Increased appetite & 04 \\
\hline Insomnia & 07 \\
\hline Tremor & 10 \\
\hline Palpitation & 15 \\
\hline Dysphagia & 12 \\
\hline Hoarseness of voice & 10 \\
\hline Easy fatigability & 05 \\
\hline & 72 \\
\hline
\end{tabular}

*P- value is less than 0.0001 , highly significant

Table 5: One year: 72 nos.of cases: (From October, 2020- Sept.2021)

\begin{tabular}{|c|c|c|c|}
\hline Age in years & Clinical presentation & Type of Tumor at diagnosis & Total \\
\hline 15-20yrs & Big swelling & 6-Colloid goiter & $9 \mathrm{nos}$ \\
\hline
\end{tabular}




\begin{tabular}{|c|c|c|c|}
\hline & Swelling +redness & 3-lymphocytic growth & \\
\hline $21-25 \mathrm{yrs}$ & $\begin{array}{c}\text { Swelling } \\
\text { Swelling +scratch }\end{array}$ & $\begin{array}{c}\text { 5-Colloid goiter } \\
\text { 3-lymphocytic infiltrate }\end{array}$ & 8 nos \\
\hline $26-30 \mathrm{yrs}$ & 0 & $\begin{array}{c}\text { 5-colloid goiter } \\
\text { 2-lymphocytic infiltrate } \\
\text { 4-follicular }\end{array}$ & 11 nos \\
\hline $31-35 \mathrm{yrs}$ & 0 & $\begin{array}{c}\text { 10-colloid goiter } \\
\text { 4-lymphocytic infiltrate }\end{array}$ & 14 nos. \\
\hline $36-40 \mathrm{yrs}$ & 0 & $\begin{array}{c}\text { 4-lymphocytic infiltrate } \\
\text { 3-Follicular }\end{array}$ & 7 nos \\
\hline $41-45 \mathrm{yrs}$ & 0 & $\begin{array}{c}\text { 3- Colloid goiter } \\
\text { 5-Follicular growth }\end{array}$ & 8 Nos \\
\hline $46-50 \mathrm{yrs}$ & 0 & $\begin{array}{c}\text { 3-lymphocytic } \\
\text { 3-Follicular } \\
\text { 1-Follicular Carcinoma }\end{array}$ & 7 Nos \\
\hline $51-55 \mathrm{yrs}$ & 0 & $\begin{array}{c}\text { 4-Colloid goiter } \\
\text { 1-Papillary carcinoma }\end{array}$ & 5 Nos \\
\hline $56-60 \mathrm{yrs}$ & & $\begin{array}{c}\text { 2-Follicular Carcinoma } \\
\text { 1-Papillary Carcinoma }\end{array}$ & 2 Nos. \\
\hline$>60 \mathrm{yrs}$ & & 1-Papillary Carcinoma & 1 Nos \\
\hline$>$ & Total & & 2 Nos. \\
\hline
\end{tabular}

Table 6: FNAC findings in our deptt. As per TBSRTC

\begin{tabular}{|c|c|}
\hline FNAC findings & Total no. of cases \\
\hline Non diagnostic (cyst fluid, only colloid, blood etc) & 02 \\
\hline Benign consistent with follicular nodule & 03 \\
\hline Goiter & 32 \\
\hline Hyshimoto's thyroditis & 16 \\
\hline Adenomatous swelling & 12 \\
\hline Atypia of undermined significance/follicular lesion of undertermined significance & 02 \\
\hline Suspicious of malignancy & 0 \\
\hline Follicular neoplasm & 03 \\
\hline Papillary neoplasm & 02 \\
\hline Medullary neoplasm & 0 \\
\hline Squmous cell carcinoma & 0 \\
\hline Carcinoma with mixed feature & 0 \\
\hline Metastatic carcinoma & 0 \\
\hline Total & 72 \\
\hline
\end{tabular}

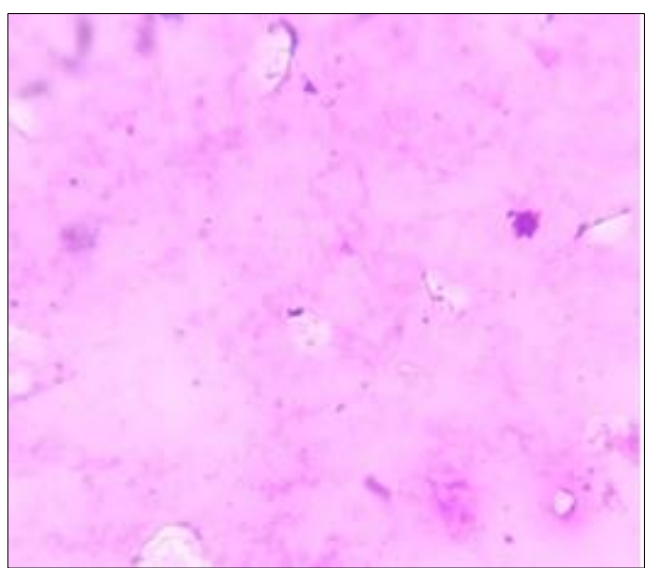

Fig 3: Simple coll oid goiter showing abundant coll oid material 40x power.

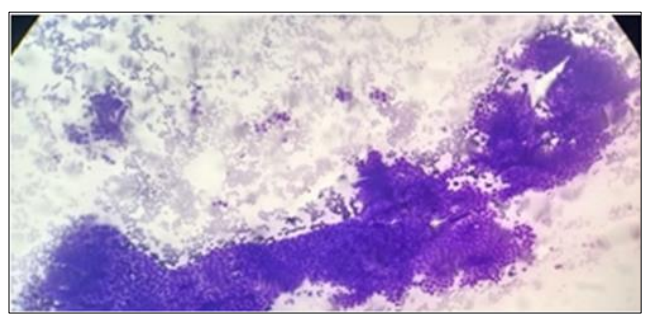

Fig 4: Papillary carcinoma, at low ower viws forming typical papillary fronts.

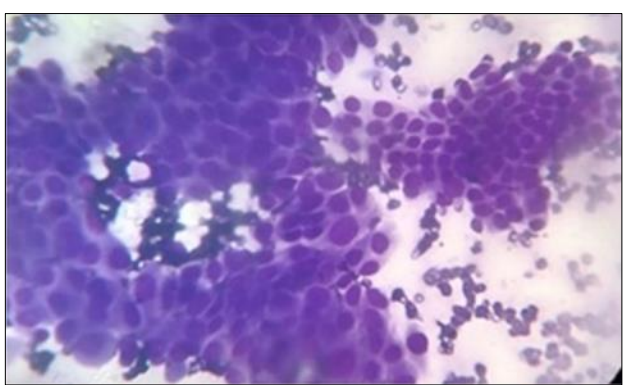

Fig 5: Showing papillary carcinoma micro-papillary with nuclear atypia 40x.

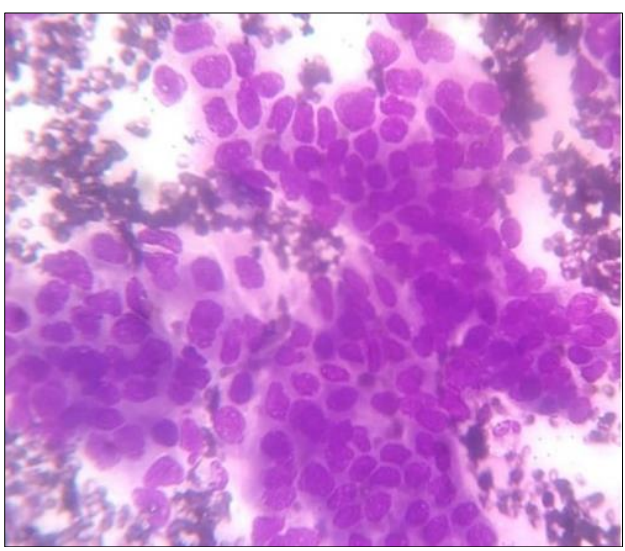

Fig 6: Follicular carcinoma arranged in cluster and macro follicle. 


\section{Discussion}

A total 72 nos. of cases were studied in our hospital during the period of October 2020 to Sept 2021. In this study non neoplastic cases were more than the cancerous lesions among all groups. Iodized product especially with salt iodization by central government although reaches the peak, but still there is deficiency in the midst of plenty ${ }^{[1]}$.

Incidence of thyroid disease is influenced by age, sex and natural geography location of the country ${ }^{[2]}$. In this study we tried to figure out the incidence of non malignant and malignant usual thyroid specimen in routine cytology deptt. of our hospital at Jorhat Medical College \& Hospital.

In our study the occurrence of non malignant cases were more than malignant cases, as has been shown by many national studies.

Tsegaye B Ergete W et al. found that nodular colloid goiter is the most prevalent thyroid disease. Papillary carcinoma is the most frequent cancer seen in his series of study. Appropriate measures should be taken to reduce the iodine deficiency states in the diet to alleviate the social and medical consequences of the disease ${ }^{[8]}$.

Kartha Priya P, Sadasivan Santha, et al. resolved that thyroid diseases has definite female predominance, with most of them occurring in an age group of 30-50 years. Multi nodular goitre remains the most common disease clinically, radiologically and cytologically. Fine needle aspiration findings and ultrasonogram findings showed moderate agreement with histopathology, which correlate with the present study ${ }^{[3]}$.

Sukumaran Renu, Jayashree et al. concluded the cytology diagnoses cases that were further classified into nondiagnostic/unsatisfactory, benign, atypia of undetermined significance/follicular lesion of undetermined significance, follicular neoplasm/suspicious for a follicular neoplasm, suspicious for malignancy and malignant as per Bethesda guide line that correlates with our sudy ${ }^{[2]}$.

Allen S Ho, Evan E Sarti, Kunal Jain S, et al. reported that The Bethesda System for Reporting Thyroid Cytopathology is the standard for interpreting fine needle aspiration (FNA) specimens. The "atypia of undetermined significance/follicular lesion of undetermined significance" (AUS/FLUS) category, known as Bethesda Category III, has been ascribed a malignancy risk of $5-15 \%$, but the probability of malignancy in AUS/FLUS specimens remains unclear which correlate with present study significantly ${ }^{[7]}$.

Gopalakrishnan UA and Menon usha V et al. reviewed the epidemiology of five common thyroid diseases in India; those were hypothyroidism, hyperthyroidism, goiter and iodine deficiency disorders, Hashimoto's thyroiditis, and thyroid cancer. This review will also briefly cover the exciting work that is in progress to ascertain the normal reference range of thyroid hormones in India that is consistent with this study ${ }^{[6]}$.

In our study it has been seen that benign lesion of thyroid followed by various neoplastic lesions of thyroid, the most common cancer was papillary carcinoma, followed by follicular carcinoma. Some studies showed the association between multinodular goiter and papillary thyroid carcinoma was high which was very much significant with our present study.

\section{Conclusion}

Midline neck mass is very usual finding in our hospital especially showed definite female predominance. The commonest age group is $3^{\text {rd }}$ to $5^{\text {th }}$ decades of life. Most of the cases presenting with painless nodule while other group associated with pain as well as pressure effects e.g. difficulty in swallowing, breathlessness, palpitation, loss of sleep, hoarseness of voice etc. clinical cases were from simple thyroid nodule to multi nodular colloid goiter associated with thyrotoxic features.

Clinical evaluation associated with blood biochemistry to FNAC. Some cases were underwent thyroid scan, U/S guided FNAC etc. FNAC being the most popular, economical, easy to perform and very useful time saving procedure to take clinical decision and follow-up. TBSRTC has now available to differentiate early benign follicular nodule, inflammatory thyroditis and malignant counterpart. Risk of malignancy could be after histopatholgical where ever possible in the same hospital and further necessary evaluation.

\section{Conflict of Interest: None}

\section{Source of Funding: Nil.}

Authors Contribution: This is a departmental work-up among the authors of the same Institute.

\section{References}

1. Text Book. "The Bethesda Systemfor Reporting Thyroid Cytopathology", 2 ${ }^{\text {nd }}$ Edi

2. Renu Sukumaran, Jayashree Kattor K, Rabindran Pillai, Preethi Ramdas. "Fine neddle aspiration cytology of thyroid lesions and its correlation with histopathology in a series of 248 patients. Indian J Surg Onco. 2014;5(3):237-41.

3. Kartha Priya P, Sadasivan Santha. "Spectrum of Thyroid Lesions and its Clinico-pathological Correlation-A Two years Study from Tertiary Care Hospital, JMSCR. 2017;05(07):25615-25622.

4. Thomas T, Sreedharan S, Khadilkar UN, Deviprasad D, Kamath MP, Bhojwani KM et al. Clinical, biochemical \& cytomorphologic study on Hashimoto's thyroiditis. Indian J Med Res. 2014;140(6):729-35.

5. Sanyal D. Spectrum of Hashimoto's thyroiditis: Clinical, biochemical \& cytomorphologic profile. Indian J Med Res. 2014;140(6):710-2.

6. Unnikrishnan AG, Menon UV. Thyroid disorders in India: An epidemiological perspective. Indian $\mathrm{J}$ Endocrinol Metab. 2011;15(6):78.

7. Allen Ho S, Evan Sarti E, Kunal Jain S, Hangjun Wang, Iain Nixon J, Ashok Shaha R et al. "Malignancy rate in thyroid nodule classified by Bethesda category III (AUS/FLUS), Thyror. 2014;24(5):832-9.

8. Tsegaye B, Ergete W. Histopathologic pattern of thyroid disease. East Afr Med J. 2003;80(10):525-8. 